\title{
Правовая аксиология русского консерватизма XIX века: потенциал влияния на современную правовую идеологию
}

\author{
${ }^{1)}$ Кузубова А.Ю., ${ }^{2)}$ Сафронова Е.В. \\ ${ }^{1)}$ Воронежский государственный педагогический университет, \\ Россия, 394043, г. Воронеж, ул. Ленина, 86 \\ ${ }^{2)}$ Белгородский государственный национальный исследовательский университет, \\ Россия, 308015, г. Белгород, ул. Победы, 85 \\ E-mail: angelinakuzubova@mail.ru; elena_safronova_2010@mail.ru
}

\begin{abstract}
Аннотация. Авторы обратились к изучению юридической природы современной правовой идеологии в контексте ее соответствия традиционным правовым ценностям отечественной культуры. Несмотря на всю важность, потенциал влияния правовых ценностей русского консерватизма на современную правовую идеологию остается мало изученным. Анализируя соотношение категорий «правовая идеология» и «позитивное право», авторы отмечают вариантность их сочетаний: в истории права преобладают факты противостояний правовых идеологий и систем позитивного права. Подчеркивается, что конфликт ценностей, ценностный вакуум могут повлечь гораздо более разрушительные последствия, нежели принятие официальной правовой идеологии, перспективы провозглашения которой порождают многочисленные споры. В результате исследования сделан вывод о необходимости институциональной комплементарности системы позитивного права и правовой идеологии, воплощающей традиционные правовые ценности.
\end{abstract}

Ключевые слова: правовые ценности, русский консерватизм, правовая идеология, правосознание, политико-правовая доктрина.

Для цитирования: Кузубова А.Ю., Сафронова Е.В. 2021. Правовая аксиология русского консерватизма XIX века: потенциал влияния на современную правовую идеологию. NOMOTHETIKA: Философия. Социология. Право, 46 (2): 343-352. DOI 10.52575/2712-746X-202146-2-343-352

\section{Legal axiology of Russian Conservatism of the XIX century: the potential of influence on modern legal ideology}

\author{
${ }^{1)}$ Angelina Yu. Kuzubova, ${ }^{2}$ Elena V. Safronova \\ 1) Voronezh State Pedagogical University, \\ 86 Lenin St, Voronezh, 394043, Russia \\ 2) Belgorod National Research University, \\ 85 Pobedy St, Belgorod, 308015, Russian Federation \\ E-mail: angelinakuzubova@mail.ru; elena_safronova_2010@mail.ru
}

\begin{abstract}
The authors turned to the study of the legal nature of modern legal ideology in the context of its compliance with the traditional legal values of Russian culture. Despite its importance, the potential influence of the legal values of Russian conservatism on modern legal ideology remains poorly understood. Analyzing the correlation of the categories "legal ideology" and "positive law", the authors note the variety of their combinations: in the history of law, the facts of the confrontation of legal ideologies and systems of positive law prevail. It is emphasized that the conflict of values, the value vacuum can lead to much more destructive consequences than the adoption of an official legal ideology, the prospects for the proclamation of which give rise to numerous disputes. As a result of the conducted research, it is concluded that the
\end{abstract}


institutional complementarity of the system of positive law and legal ideology embodying traditional legal values is necessary.

Keywords: legal values, Russian conservatism, legal ideology, legal consciousness, political and legal doctrine.

For citation: Kuzubova A. Yu., Safronova E. V. 2021. Legal axiology of Russian conservatism of the XIX century: the potential of influence on modern legal ideology. NOMOTHETIKA: Philosophy. Sociology. Right, 46 (2): 343-352 (in Russian). DOI 10.52575/2712-746X-2021-46-2-343-352

\section{Введение}

Исследование механизмов функционирования правовых ценностей предполагает обращение к проблематике современной правовой идеологии в контексте ее влияния на правовую сферу. Именно государственно-правовые идеологии тысячелетиями обусловливали эволюцию государств и обществ, продуцируя идеи и ценности, воздействующие на разные уровни правосознания. Освоение правовой действительности предопределено аксиологическими приоритетами, и задачей правовой идеологии является направление субъекта через формирование его мировоззрения. Основное значение правовой идеологии заключено в ее способности придавать ценностям и идеям общезначимый характер и тем самым создавать модели социально полезного поведения. Несмотря на важность изучения мировоззренческих основ правовой жизни, обращение к ценностным аспектам правовой идеологии происходит не так часто. Исключением являются работы Р.И. Байгутлина, Г.А. Бурнашева, В.Ю. Мельникова и некоторых других авторов [Байгутлин, 2013; Мельников, 2016; Бурнашев, 2018].

Российская действительность на фоне разрушения советской системы парадоксальным образом восприняла марксистскую концепцию идеологии как «ложного сознания». В условиях объявленной деидеологизации была уничтожена ценностная матрица социалистической государственности, при этом, в рамках требований ст. 13 Конституции Российской Федерации, любая государственная или обязательная идеология оказались под запретом, что дестабилизировало правовые начала общества. Подобный вакуум в отражении и оценивании правовых явлений в едином русле порождает проблемы в формулировании правовых ценностей, вызывает трудности в восприятии и претворении в жизнь адекватных эпохе идеалов, целей и ориентиров. К тому же сохраняется опасность заполнения возникших пустот правовыми антиценностями как определяемыми культурой формами негативного отношения субъекта к правовой системе общества, которые обусловливают юридическую оценку событий и выбор соответствующих форм поведения.

Эклектичность, фрагментарность представлений о праве не способствуют гармоничному развитию правовой системы, ведь формирование правового мышления должно исходить из определенных ценностей-ориентиров. Представляется, что сильное государство должно формулировать и транслировать правовую идеологию, отражающую национальные идеи о праве и правовой системе общества. Функционирование правовых ценностей через включение в правосознание и деяния субъектов обеспечивается в значительной степени правовой идеологией. Без указанного механизма возникают проблемы с легитимацией позитивного права, затрудняется трансформация правовых ценностей в нормативные установки и соответствующие им модели правомерного поведения. Весьма точным нам представляется высказывание А.В. Полякова, который заметил: «Право не существует вне человеческого сознания, право становится правом, лишь "преломляясь" сквозь сознание социального субъекта... Только через свое когнитивное осмысление и ценностную интерпретацию правовые тексты получают правовую легитимацию и трансформируются в нормативные установления, способные воздействовать на волю и, соответственно, на поведение субъектов, определяя его как правовое» [Поляков, 2004, с. 385]. По нашему мнению, Россия 
испытывает потребность в создании современной правовой идеологии, ориентированной на совершенствование способов правовой социализации, достижение высокого уровня правовой культуры, согласование индивидуальных и социальных начал, разума и духа, права и правды, что предопределяет актуальность обращения к изучению юридической природы современной правовой идеологии в контексте ее соответствия традиционным правовым ценностям отечественной культуры.

\section{Правовая идеология и ее аксиологическая структура}

Некоторые авторы под правовой идеологией понимают «систематизированные представления о правовой действительности, в основе которых лежат определенные ценностные посылки» [Поляков, Тимошина, 2005, с. 159]. Т.В. Синюкова считает, что правовая идеология характеризуется целенаправленным, «научным либо философским осмыслением права как целостного социального института, не в отдельных его проявлениях, а в качестве самостоятельного элемента общества» [Синюкова, 2002, с. 614]. Правовая идеология как элемент правосознания представляет собой вместилище правовых идей, выражающих определенную систему ценностей. В функциональном аспекте это механизм, преобразующий правовые идеи и ценности в нормативные установки. В широком смысле это совокупность теорий, концепций, доктрин о праве и правовом развитии, способствующих формированию правовых ценностей и выработке определенных правовых установок, а также механизмов, внедряющих указанные концепты в общественное сознание. Такая идеология направлена на легитимацию государственной власти и существующего правопорядка, формирование юридического мировоззрения, создание единого образа окружающей правовой действительности, обеспечение национальной безопасности и т.п. При официальной поддержке правовая идеология может не только формулировать цели развития правовой системы, но и разрабатывать соответствующие правовые конструкции, определяющие матрицу юридической практики.

Генезис и развитие юридического мировоззрения происходит через приращение сознания правовыми представлениями, правовыми ценностями, понятиями и идеями. Правовая идеология, действуя посредством функционирования системы правовых ценностей, запускает процессы правовой оценки, что приводит к формированию правовых суждений. Вместе с тем, анализируя соотношение категорий «правовая идеология» и «позитивное право», необходимо отметить вариантность их сочетаний: от полного расхождения компонентов до максимального включения. Истории права известны, в большей степени, примеры противостояний правовых идеологий и систем позитивного права. Напротив, полное воплощение той системы идей и ценностей, которые образуют содержание правовой идеологии, в правовых нормах и институтах принципиально невозможно. Контекст и специфика субъективной интерпретации предопределяют разнообразие подходов в трактовке идеологических компонентов.

Аксиологическая структура правовой идеологии представлена несколькими уровнями: можно выделить своеобразный ярус фундаментальных правовых ценностей, выражающих основные концепты идеологии. Именно здесь происходит синтез нравственных и правовых ценностей, обусловливающий легитимацию правовых идей со стороны нравственных и религиозных императивов. Следующий уровень выражен правовыми ценностями, относящимися к функционированию институтов позитивного права. Данный срез представлен преимущественно профессиональным и доктринальным правосознанием специальных субъектов. Доктринальное правосознание строится на доктринах, в которых формулируется определенное понимание права, носящее конструирующий характер. Профессиональное правосознание выражено в представлениях о праве, убеждениях юристов, сформированных специальными знаниями и опытом практической деятельности. Такое право- 
сознание носит логико-нормативный характер, четкую предметную направленность, особые формы внешнего выражения. В-третьих, можно выделить уровень массовый или обыденный, основанный на восприятии видимых концептов права в контексте культурно-исторических, социально-политических, национальных и иных особенностей бытия. Обыденный уровень является одновременно самым эклектичным, реактивным и в то же время сохраняющим и транслирующим архетипы национального правосознания, что обеспечивает передачу идейно-ценностных компонентов последующим поколениям.

Дифференциация правовых идеологий возможна по различным основаниям. Во-первых, можно выделить официальные правовые идеологии, воплощенные в институтах и нормах позитивного права, и неофициальные правовые идеологии, имеющие с ними расхождения. Во-вторых, разграничение правовых идеологий происходит по лежащим в их основаниях учениям и ценностям, закладывающим алгоритмы восприятия социальных феноменов. В сущности, речь идет об онтологических конструкциях, представляющих собой попытки наиболее общего описания универсума, места человека в нем, смысла существования человека. Довольно распространенной является классификация правовых идеологий в контексте разграничения типов правопонимания, во-первых, на естественно-правовые и позитивистские, во-вторых - на этатистские, социологические, психологические и др.

\section{Коллизия основных правовых ценностей русского консерватизма и европейского либерализма}

Обращение к компаративному анализу теоретических основ правовых ценностей отечественного консерватизма и европейского либерализма XIX века позволяет критически осмыслить сложившуюся монополию системы европейских правовых ценностей, акцентировать внимание на присутствии существенных отличий аксиологических базисов правовых систем, восходящих из разных культурно-религиозных традиций. Ценностные слои правовой идеологии, представленные главными правовыми идеями и ценностями, предопределяют своеобразие указанных систем. Выстраиваемые иерархии, особенности сочетания аксиологических компонентов формируют контуры и содержание идеологий.

Краеугольным камнем либеральной парадигмы выступает частный интерес: в атомизированном западном обществе происходит олицетворение права в его исключительно юридическом смысле (в нормативном выражении) и права как формы стихийной жизни общества. Условия исторического развития стран Запада обусловили формирование представлений о праве как первооснове общества, охраняющей собственность и различные формы хозяйственной деятельности. Экономические предпосылки в значительной степени способствовали созданию учения о правовом государстве. Исходным началом, генерирующим размышления о свободе, в частности о свободе волеизъявления, в консервативной политико-правовой доктрине была тема отрицания антропоцентризма. Данное начало предопределило негативное отношение к идее абсолютизации прав человека, свойственной либеральному правопониманию. Указанные и иные отличия позволяют отнести либеральную правовую идеологию к типу персоноцентристких, а консервативную - к типу социоцентристских идеологий (ориентированных на коллективные формы диалога с властью). Правовая идеология либерализма исходит из первичности идей свободы, прав личности, частного блага, тогда как в консервативном направлении доминируют ценности справедливости, правды, ответственности и порядка [Кузубова, 2021, с. 21].

Инициированные в начале 1990-х годов XX века в России процессы деидеологизации на самом деле имели своей целью закрепление исключительности и безальтернативности либеральной идеологии. Объявление либеральной демократии и ее ценностей в качестве единственно верной модели, к которой всем народам и государствам необходимо стремиться, лишило человечество выбора и заставило принести в жертву духовные ценности, 
заменив их экономическими потребностями и интересами. В обществе потребления культура и нравственные идеи отошли на задний план, ведь либерализм «освободил» человека от нравственных императивов и духовных идеалов.

Правовая идеологии представляет собой модель окружающей правовой действительности через формирование своеобразного каркаса общественного правосознания. Современную отечественную правовую идеологию мы можем определить как мировоззрение либерального типа. Положения Конституции Российской Федерации, принятой всенародным голосованием 12.12.1993 с изменениями, одобренными в ходе общероссийского голосования 01.07.2020, идентифицируют Россию как демократическое федеративное правовое государство. Высшей ценностью провозглашаются права человека, что, наряду с концептами свободы личности, идеями правового государства, демократии, гарантиями защиты частной собственности, ограничением влияния государства и церкви на общество, предопределяет либеральную сущность отечественного Основного закона. В отечественной юридической науке монополия либеральной правовой идеологии привела к тому, что идея прав человека девальвировала диалектически взаимосвязанную категорию обязанности, тем самым ослабив практическое действие этих остро нуждающихся в согласовании феноменов.

В тексте Основного закона наша страна определяется как социальное государство, политика которого направлена на создание условий, обеспечивающих достойную жизнь и свободное развитие человека. Но указанные характеристики не соответствуют матрице правовой реальности как в ретроспективном, так и в перспективном аспекте, что нивелирует ценностный потенциал конституционных положений. Несовпадение декларируемых положений с отражением правовой действительности порождает противоречия. Главной проблемой обновленной Конституции РФ остается отсутствие объединяющей идеи, способной выстроить смыслообразующую логически непротиворечивую композицию, устраивающую российское общество. Конфликт ценностей, ценностный вакуум может привести к гораздо более разрушительным последствиям, нежели принятие официальной государственной идеологии, перспективы институционального закрепления которой порождает многочисленные споры.

В соответствии с положениями Конституции Российской Федерации наше государство лишено возможности создания, введения и защиты государственной идеологии, а значит, ответственность за подобные действия переложена на иных субъектов правоотношений. Но кому по силам такое бремя? Такие задачи априори не решаемы частными субъектами, тем более в условиях официального провозглашения приоритета правового и нравственного индивидуализма. Делегирование права выбора идеологических моделей развития институтам гражданского общества в условиях полного отсутствия законодательно оформленных ориентиров затрудняет решение указанной задачи. Да и сами надежды на саморегуляцию гражданского общества, способную минимизировать вмешательство государства, представляются несвоевременными.

Долгий процесс борьбы за права и свободы человека увенчался успехом: эти ценности обрели всемерное закрепление, приоритет и защиту, но в этой битве мы понесли потери - исчезла сама личность с ее уникальным миром. Остались только наборы требований, направленных на создание минимума необходимых жизненных условий человеческого существования [Лукашева, 1979, с. 22]. Вместе с тем в центре сферы осуществления прав и свобод должен пребывать человек, воспринимающий нормы права, осознающий правовые ценности и тем самым генерирующий правореализационные механизмы. Новая реальность должна рождаться в синтезе общечеловеческих ценностей и русской духовной культуры вокруг личности, органично сочетающей нравственные и правовые ценности, частью унаследованные через традицию от предков, частью исходящие из современного образа жизни. Приведение в порядок правового поля достижимо не в контексте усиления нормативного 
регулирования всех сфер жизни, а через обращение к человеческому в человеке, что возможно с опорой на аксиологию русского консерватизма. Свобода в консервативной политико-правовой доктрине рассматривалась как внутренний выбор, творческий синтез сознательного и бессознательного, не привязанный к формально-юридическим категориям и процессам, проявляющийся в возможности свободно приобретать и нести юридические обязанности. Консервативное понимание свободы отличалось бинарностью, проявляющейся в разграничении содержательного компонента и эмпирической реальности. Целостность и единство внутренней и внешней свободы, по мнению идеологов консерватизма, подтверждала тезис о том, что право не следует выводить из одной идеи свободной воли человека, данный феномен необходимо соотносить с традицией, культурой общества, его нравственно-религиозными ценностями.

Не следует редуцировать подходы к свободе, выработанные мыслителями отечественного консерватизма XIX века, ведь они не отрицали ценность свободы. Речь шла о необходимости слияния и гармонизации свободы и нравственности в личностном бытие и о том, что контуры свободы предопределены нравственными и правовыми ценностями. Свобода в консервативном понимании означала устремленность личности и идентифицируемой с ней культурной общности к развитию в соответствии с идеалами правды и справедливости. Мы можем констатировать, что в доктрине русского консерватизма исследуемого периода была актуализирована задача этизации свободы. Предложена концепция развитой свободы с перемещением внимания с прав и свобод на ответственность. Последняя определялась как формируемая в процессе нравственного становления через компоненты совести, вины, долженствования, справедливости модель сложных взаимоотношений между личностью, обществом, государством. В консервативной политико-правовой доктрине на первое место выдвигалась внутренняя (позитивная) ответственность, тогда как ретроспективной ответственности в виде государственного принуждения уделялось меньшее внимание [Кузубова, 2020, с. 148]. Ведь ответственный человек по внутреннемуубеждению, вне принудительных механизмов исполняет свои обязанности.

В ядре правовых ценностей особое место исторически отводится справедливости, что обусловило необходимость уточнения подходов к данной категории в контексте консервативного правопонимания и потенциала воздействия на содержание современной правовой идеологии. Либеральная политико-правовая доктрина XIX века в восприятии справедливости делала акцент на равенстве, одинаковых критериях в обеспечении прав, свобод, установлении обязанностей. Консервативная парадигма исследуемого периода отождествляла справедливость с необходимым воплощением нравственности в праве, стремлением к общему благу на фоне гармоничного сочетания прав и обязанностей. Рациональное познание справедливости через нормативные предписания не представлялось возможным, ведь это сфера действия христианской морали. Из такого восприятия феномена справедливости вытекало отношение к закону как потенциальному отражению не только начал добра, но и зла. Действительно, система существующих социальных ценностей (в том числе правовых) не всегда находит воплощение в законе, законодательство часто меняется, не исполняется, нарушается, в силу чего уровень содержания справедливости в позитивном праве меняется. Доктрина консерватизма актуализировала проблему несправедливости принудительного уравнения людей. Обращалось внимание на недопустимость одинаковости, невозможности регуляции всех сфер жизни с помощью общественного договора. Можно согласиться с этим, действительно, закон должен учитывать конкретные жизненные обстоятельства и специфику субъекта, что особенно актуально в процессе его реализации на практике.

В системе правовых ценностей и принципов регулирования справедливость должна иметь несомненный приоритет. Необходимо уходить от позитивистских трактовок, умаляющих значение справедливости, в контексте которых подчинение несправедливому закону представляется более предпочтительным, чем нарушение такого закона. Законодательство можно считать правовым только при условии воплощения в нем идеи справедливости. При 
этом сама справедливость должна пониматься как основанное на социально-правовом опыте пропорциональное воздаяние за дела, сближающее идеал и правовую реальность.

Одним из несомненных достоинств консервативной политико-правовой доктрины является создание особого концептуального подхода к личности, для которой сверхважно подчинение интересам общества и государства, актуально бытие в качестве части коллективного целого. Уникальность характера русского человека является следствием исторически сложившегося синтеза православной культуры и традиционного патриархального уклада жизни. Такая личность отдает предпочтение духовно-нравственным началам в контексте оценки правовых явлений с точки зрения их соответствия справедливости, девальвируя роль формально-юридических начал. Это постоянное противостояние «Закона» и «Благодати», «внешней» и «внутренней» правды. Отсутствие диалога позитивного права с надправовыми ценностями справедливости, правды, свободы, к сожалению, оборачивается попранием закона в индивидуальном правосознании. Решение указанной проблемы возможно только через последовательное развитие, воспитание правосознания в духе традиций отечественной правовой аксиологии.

Именно в правосознании конкуренция права и закона обретает черты скептического отношения к праву, девальвации его социальной ценности. В периоды коренных переломов, разрушения традиционных социальных форм и институтов на первое место всегда выходят правовые ценности и идеалы, максимально включающие в себя понятные и близкие каждому нравственные начала. Деформация ценностных ориентаций личности неизбежна в условиях продолжающегося противостояния правовых и нравственных, государственных и индивидуальных ценностей. В структуре правосознания особое место, наряду с рациональным уровнем в виде правовой идеологии, волевым уровнем, воплощенным в виде правовой психологии, занимает уровень правовой аксиологии в виде ценностно-правовых ориентаций личности. Если исключить последний компонент - начинают проявляться сбои в развитии всего правосознания. Ценностная аксиосфера на личностном и коллективном уровне детерминирует все виды правосознания. В свою очередь, синтез правовых и нравственных ценностей в структуре правосознания обеспечивает правильный выбор в контексте социального взаимодействия.

Неправовое содержание российского правового сознания обусловлено исторически сложившимся ограниченным распространением правовых отношений в общественной жизни. Абсолютизация роли правового компонента в механизме социального регулирования является процессом с неоднозначными последствиями. Расцвет юриспруденции, проникновения нормативного регулирования во все сферы общественной жизни, к сожалению, является последствием восполнения дефицита нравственности. Как писал К.Н. Леонтьев, «репрессивные меры не могут быть сами по себе целью; они - только временный прием для того, чтобы люди "не мешали" приготовить что-нибудь более прочное в будущем» [Леонтьев, 2003, с. 556]. Утрата правом его нравственного измерения привела к его ассоциированию с принуждением, силой, бездушным инструментом механического регулирования. Именно перекос в сторону «буквы» закона неоднократно приводил к репрессивным практикам, о чем свидетельствуют факты отечественной и зарубежной истории.

Современные либеральные правоидеологические тенденции транслируют установки о сверхценности права на фоне обусловленности норм нравственности, представлений о добре и зле именно правом. Подобные теории подрывают сложившиеся традиционные иерархии ценностей, дестабилизирует правовые ценностные ориентации личности. Лакуны в правосознании являются следствием искусственной компрометации существующих правовых ценностей при отсутствии новых идей, принимаемых обществом. Невозможность понять и принять многие либеральные правовые ценности неизбежно усиливает социальную напряженность. 
Постоянно расширяется предмет правового регулирования общественных отношений, происходит детальная регламентация многих сфер, появляются новые отрасли и институты права. Усложнение происходит посредством увеличения числа нормативно-правовых актов. Но количество законов не способно перейти в качество правового регулирования, тем более через разрастание массива законов и подзаконных актов, неизбежно ведущее к сложностям функционирования. Как бы технически не был совершенен закон, его воздействие на обыденное правосознание несопоставимо с влиянием разделяемых значительной частью общества идей и ценностей. Сама легитимация права, осознание его ценности также происходит через действие правовой идеологии на общественное и профессиональное сознание в контексте аксиологических базисов. Тем самым закрепляются представления о положительном значении правового регулирования, его инструментальной значимости и безальтернативности.

Мы согласны с тезисом, что не все сферы жизни человека и общества подлежат законодательной регламентации, но в то же время нельзя умалять возможности права, идеализируя потенциал иных регуляторов общественных отношений. К сожалению, современный уровень развития социальных систем не позволяет ослабить упорядочивающую функцию права. Даже мораль и нравственность нуждаются в защите со стороны права и государства, что особенно востребовано в сложные периоды истории.

\section{Заключение}

Правовая идеология должна быть внутренне непротиворечивой, исключающей коллизии и неверные интерпретации. Обеспечение стабильного развития возможно только в условиях сохранения с помощью юридических и неюридических механизмов сложившихся в обществе традиционных ценностей. Вариант - официально-правовое закрепление в качестве юридических категорий базовых ценностей идеологии. При этом в центре должна стоять объединяющая общество национальная идея. На современном этапе главные ценности традиционной правовой идеологии - правда, долженствование, справедливость, порядок во-первых, не получили адекватного их значению научного осмысления, во-вторых, не нашли отражения в нормативно-правовых актах.

Взаимовлияние и взаимозависимость правовых ценностей и правовой идеологии не вызывают никаких сомнений. Право в своем историческом развитии обеспечивает охрану конкретных правовых ценностей. Специфический культурный код русского человека включает и своеобразные правовые ценности, весьма точно выявленные и отраженные в отечественной консервативно-правовой доктрине. Мыслители консерватизма акцентировали внимание на том, что разрушение нравственно-правовых ценностей русского человека неизбежно обернется гибелью государства. Рассматривая проблематику правосознания, И.А. Ильин указывал: «Необходимо приблизить право к народу, чтобы укрепить массовое правосознание, чтобы народ понимал, знал и ценил свои законы, чтобы он добровольно соблюдал свои обязанности и запретности и лояльно пользовался своими полномочиями. Право должно стать фактором жизни, мерою реального поведения, силою народной души [Ильин, 1993, с. 31]. Указанное представляется достижимым путем синтеза правовой идеологии, воплощающей традиционные правовые ценности, адекватные потребностям времени, и системы позитивного права.

В контексте бытия феноменов права актуально соединение идеи и формы. Необходима комплементарность действия системы позитивного права и «живущих» в правосознании идей и ценностей, в противном случае неизбежна низкая эффективность работы правовых институтов. Правовые ценности должны выступать «дорожной картой» на всех стадиях правового регулирования: правотворчества, возникновения, изменения, прекращения правоотношения, реализации права, только тогда механизм правового регулирования станет подлинно действенным. 


\section{Список литературы}

1. Байгутлин Р.И. 2013. Ценностно-идеологический фактор в правовом регулировании. Вестник Челябинского государственного университета. Право, 27 (318): 5-10.

2. Бурнашев Г.А. 2018. Ценностные аспекты правовой культуры и правовой идеологии, их влияние на правоприменительную политику. Молодой ученый, 48 (234): 107-110.

3. Ильин И.А. 1993. О сущности правосознания. М., Рарогь, 235 с.

4. Кузубова А.Ю. 2021. Правовые ценности как критерий дифференциации политико-правовых доктрин русского консерватизма и европейского либерализма XIX века. Пробелы в российском законодательстве, 14 (1): 18-24.

5. Кузубова А.Ю. 2020. Правовые ценности русского консерватизма ХІХ века: монография. М., Юрлитинформ, 208 с.

6. Леонтьев К.Н. 2003.Чем и как либерализм наш вреден. В кн.: Храм и церковь. М., Издательство АСТ: 531-556.

7. Лукашева Е.А. 1979. Права человека и культура. В кн.: Конституция СССР и правовое положение личности. М., Изд-во ИГиП АН СССР: 19-31.

8. Мельников В.Ю. 2016. Право на конституционную правовую идеологию государства. Юридические исследования, 3: 1-6.

9. Поляков А.В. 2004. Общая теория права: проблемы интерпретации в контексте коммуникативного подхода. СПб., Изд. дом С.-Петерб. гос. ун-та, 863 с.

10.Поляков А.В., Тимошина Е.В. 2005. Общая теория права. СПб., Издательский Дом С. Петерб. гос. ун-та, 472 с.

11.Синюкова Т.В. 2001. Правосознание и правовое воспитание. В кн.: Теория государства и права: учебное пособие. М., Юристъ: 611-625.

\section{References}

1. Baygutlin R.I. 2013. Tsennostno-ideologicheskiy faktor v pravovom regulirovanii [The valueideological factor in legal regulation]. Vestnik Chelyabinskogo gosudarstvennogo universiteta. Pravo, 27 (318): 5-10.

2. Burnashev G.A. 2018. Tsennostnye aspekty pravovoy kul'tury i pravovoy ideologii, ikh vliyanie na pravoprimenitel'nuyu politiku [Value aspects of legal culture and legal ideology, their impact on law enforcement policy]. Molodoy uchenyy, 48 (234): 107-110.

3. Il'in I.A. 1993. O sushchnosti pravosoznaniya [On the essence of legal consciousness]. M., Publ. Rarog, 235 p.

4. Kuzubova A.Yu. 2021. Pravovye tsennosti kak kriteriy differentsiatsii politiko-pravovykh doktrin russkogo konservatizma i evropeyskogo liberalizma XIX veka [Legal values as a criterion for differentiating the political and legal doctrines of Russian conservatism and European liberalism of the XIX century]. Probely v rossiyskom zakonodatel'stve, 14 (1): 18-24.

5. Kuzubova A.Yu. 2020. Pravovye tsennosti russkogo konservatizma XIX veka: monografiya [Legal values of Russian conservatism of the XIX century: monograph]. M., Publ. Yurlitinform, 208 p.

6. Leont'ev K.N. 2003.Chem i kak liberalizm nash vreden. [What and how our liberalism is harmful]. In: Khram i tserkov' [The Temple and the Church]. M., Publ. AST: 531-556.

7. Lukasheva E.A. 1979. Prava cheloveka i kul'tura. [Human rights and culture]. In: Konstitutsiya SSSR i pravovoe polozhenie lichnosti [The Constitution of the USSR and the legal status of the individual]. M., Publ. IGiP AN SSSR: 19-31.

8. Mel'nikov V.Yu. 2016. Pravo na konstitutsionnuyu pravovuyu ideologiyu gosudarstva [The right to the constitutional legal ideology of the state]. Yuridicheskie issledovaniya, 3: 1-6.

9. Polyakov A.V. 2004. Obshchaya teoriya prava: problemy interpretatsii v kontekste kommunikativnogo podkhoda [General theory of law: problems of interpretation in the context of a communicative approach]. SPb., Publ. S.-Peterb. gos. un-ta, 863 p.

10. Polyakov A.V., Timoshina E.V. 2005. Obshchaya teoriya prava [General theory of law]: Uchebnik. SPb., Publ. S. -Peterb. gos. un-ta, 472 p.

11. Sinyukova T.V. 2001. Pravosoznanie i pravovoe vospitanie. [Legal awareness and legal education]. In: Teoriya gosudarstva i prava [Theory of State and Law]. M., Publ. Yurist: 611-625. 


\section{ИНФОРМАЦИЯ ОБ АВТОРАХ}

Кузубова Ангелина Юрьевна, кандидат юридических наук, доцент кафедры философии, экономики и социально-гуманитарных дисциплин Воронежского государственного педагогического университета, г. Воронеж, Россия

Сафронова Елена Викторовна, профессор, доктор юридических наук, профессор кафедры конституционного и международного права Белгородского государственного национального исследовательского университета, г. Белгород, Россия

\section{INFORMATION ABOUT THE AUTHORS}

Angelina Yu. Kuzubova, PhD in Law, Associate Professor of the Department of Philosophy, Economics and Social and Humanitarian Disciplines, Voronezh State Pedagogical University, Voronezh, Russia

Elena V. Safronova, Professor, Doctor of Law, Professor of the Department of Constitutional and International Law, Belgorod National Research University, Belgorod, Russia 